University of Wollongong

Research Online

Faculty of Engineering and Information

Faculty of Engineering and Information

Sciences - Papers: Part A

Sciences

2016

Effect of grain size on springback and system energy in micro V-bending with phosphor bronze foil

\author{
Zhi Fang \\ University of Wollongong, zf548@uowmail.edu.au \\ Zhengyi Jiang \\ University of Wollongong, jiang@uow.edu.au \\ Xiaogang Wang \\ Taiyuan University of Science and Technology \\ Cunlong Zhou \\ Taiyuan University of Science and Technology, zcunlong@163.com \\ Xianming Zhao \\ Northeastern University
}

See next page for additional authors

Follow this and additional works at: https://ro.uow.edu.au/eispapers

Part of the Engineering Commons, and the Science and Technology Studies Commons

Research Online is the open access institutional repository for the University of Wollongong. For further information contact the UOW Library: research-pubs@uow.edu.au 


\title{
Effect of grain size on springback and system energy in micro V-bending with phosphor bronze foil
}

\begin{abstract}
In this paper, the effect of grain size on springback in the micro V-bending process of phosphor bronze foil (face-centered cubic structure) is investigated. Grain size effect is expressed by the ratio of material thickness $(T)$ to average grain size (D), and these T/D values are divided into three groups: larger than 1 , less than 1 , and approximately equal to 1 . It has been found that springback angles were the lowest when $T / D \approx 1$. Electron backscattering diffraction (EBSD) measurement results show that the twinning boundaries change with the ratios of T/D before and after bending. When T/D $>1$, the high relative frequency of $\Sigma 3$ implies that the specimen has a high system energy, which can result in large springback behavior. The equal relative frequencies of $\Sigma 3$ for specimens with three ratios also prove that twinning boundaries can be regarded as an indicator of system energy. The effect of grain size on grain reorientation during bending is also discussed, and it was found that the least quantities of high surface energy $\{110\}$ planes in the $T / D \approx 1$ material could contribute to the least springback angles.
\end{abstract}

\section{Keywords}

grain, springback, system, effect, energy, foil, micro, size, v, bending, phosphor, bronze

\section{Disciplines}

Engineering | Science and Technology Studies

\section{Publication Details}

Fang, Z., Jiang, Z., Wang, X., Zhou, C., Zhao, X., Zhang, X. \& Wu, D. (2016). Effect of grain size on springback and system energy in micro V-bending with phosphor bronze foil. Metallurgical and Materials Transactions A: Physical Metallurgy and Materials Science, 47 (1), 488-493.

\section{Authors}

Zhi Fang, Zhengyi Jiang, Xiaogang Wang, Cunlong Zhou, Xianming Zhao, Xiaoming Zhang, and Di Wu 
Effect of grain size on springback and system energy in micro V-bending with phosphor bronze foil

Zhi Fang ${ }^{\mathrm{a}}$, Zhengyi Jiang ${ }^{\mathrm{a},{ }^{*}}$, Xiaogang. Wang ${ }^{\mathrm{b}}$, Cunlong. Zhou ${ }^{\mathrm{b}}$, Xianming Zhao ${ }^{\mathrm{c}}$, Xiaoming Zhang $^{\mathrm{c}}$, $\mathrm{Di} \mathrm{Wu}{ }^{\mathrm{c}}$

${ }^{a}$ School of Mechanical Materials and Mechatronic Engineering, University of Wollongong,

Wollongong, NSW 2522, Australia

${ }^{\mathrm{b}}$ Shanxi Provincial Key Laboratory on Metallurgical Device Design and Theory, Taiyuan University of Science and Technology, Shanxi 030024, China

$I^{c}$ The State Key Laborateory of Rolling and Automation, Northeastern University, Shenyang, , Australia

* Corresponding author. Tel: +612 42214545

E-mail address: jiang@uow.edu.au (Zhengyi Jiang)

Abstract: In this paper, effect of grain size on springback in micro V-bending process of phosphor bronze foil (face centered cubic structure) was investigated. Grain size effect is expressed by the ratio of materials' thickness $(T)$ to average grain size $(D)$, and their $T / D$ values are divided-designed into three groups: larger than 1, less than 1 and approximately equal to 1 . It is found that springback angles were the lowest when $T / D \approx 1$. Electron back-scattering diffraction (EBSD) measurement results show that the twinning boundaries change with the ratios of $T / D$ before and after bending. When $T / D>1$, the high relative frequency of $\Sigma 3$ implies that the system-specimen has a high system energy, which can result in large springback behaviour. The equal relative frequencies of $\Sigma 3$ after bending for three ratios' specimens also prove that twinning boundaries can be regarded as an indicator of system energy. Moreover, the effect of grain size on grain reorientation during bending was discussed, and the least quantities of high surface energy $\{110\}$ planes in the $T / D \approx 1$ material could contribute to the least springback angles.

Keywords: Grain Size effect; Electron back-scattering diffraction (EBSD); System energy; Twinning boundaries; Micro V-bending; Surface energy 


\section{Introduction}

Size effects have become-an increasingly one of the most valuable and popular research topics in micromanufacturing in recent years. Correspondingly, the relevant results prompt the development of microforming technologies where size effects are playing a significant role in deformation behaviours. Size effects can be categorised into three types: density size effect, shape size effect and microstructure size effect [1]. The first two size effects have been-Grain size effect belongs to Formatted: Font color: Red microstructure size effect and is easy to realise and control so that it has been applied by many researchers. attracts widespread attention.

Geiger et al. [2] and Engel et al. [3] summarised early studies and achievements on microforming with the trend of miniaturisation in the beginning of $21^{\text {st }}$ century, and Vollertsen et al. [4] and Fu et al. Formatted: Superscript

[5] reviewed the state-of-the-art microforming progress and advanced technologies individually in recent years. With the advance of micro metal parts and their applications, downstream assembly is confronted with a problem: springback phenomenon which is inevitable in metal processing [6]. As springback can produce unexpected geometric errors, it can cause difficulties when assembling deformed parts. Therefore, a large amount of research has been conducted on springback prediction and compensation in terms of experiments and simulations [7-10]. These valuablevalued achievements have helped people obtain a better understanding of this unique phenomenon. However, it is also widely accepted that the conventional processing theories cannot be directly applied on microforming field. Hence, several studies on springback in microforming have been conducted: Gau et al. [11] studied the relationship between the ratio of thickness and grain size and springback angles by three points bending with annealed brass thin sheet, and concluded that when the thickness of material is less than $350 \mu \mathrm{m}$, the conventional springback theory cannot be applicable. Liu et al. [12] modelled three points bending with commercial finite element (FE) software ABAQUS/standard. The elastic properties in the simulation were connected with the elastic anisotropy which represents different Young's moduli in different grain orientations.-_Fang et al. [13] combined the Voronoi tessellations and grain heterogeneity in a finite element (FE) model to offer more accurate springback 
predations for micro V-bending. Gupta et al. [14]_proposed a crystal plasticity model considering $\underline{\text { strain gradient hardening to investigate the impact of grain orientation }\langle 110\rangle \text { and }\langle 100\rangle \text { on }}$ springback. Moreover, Jiang et el. [15] studied grain size effect on springback of microtube in press bending, and they found that grain subdivision could make contribution to the reduction of springback.

Chen et al. [16] conducted micro V-bending with different $T / D$ ratios' ferrum specimens and discussed the relationship between the $T / D$ and bending behaviours. Similarly, Wang et al. [17] investigated the grain size effect on springback in micro U-bending. They also proposed a constitutive model based on the surface layer model to study the materials' mechanical response, and linked it with springback behaviour. Diehl et al. [18] performed free bending test to find that the scatter of springback angles in coarse-grained material was greater than that in the fine-grained one.[9]Recently, increasing numbers of research are focusing on the grain structure [19] and grains' stress-strain state $[20,21]$ to explain the correlation between the grain size effect and springback.

Previous studies $[11,16,18]$ have proved that the ratio $T / D$ is a wide-applied indicator-evaluation Formatted: Font color: Text 1 parameter for studying the relationship between the the grain size effect and springback. However, it is also found that there is a lack of research on grain size effect when the ratio is around 1 (greater than 1 , less than 1 and equal to 1 ). Although these three values are small, what these three ratios reflect are three different special microstructural features: a few grains exist in specimen's thickness direction, one grain exists in thickness direction and one partial grain in thickness direction, respectively. Therefore, from this point, the focus of this research is to investigate and compare the effects of $T / D$ ratios on microstructural features, their interfacial energies and their deformation results during micro V-bending. 


\section{Experimental procedure}

\subsection{Heat treatment}

Phosphor bronze C5191 foil from cold rolling with thickness of $70 \mu \mathrm{m}$ was employed to conduct this research due to its wide application in microforming industry. The chemical compositions of material are displayed in Table 1.

Table 1 Chemical compositions of phosphor bronze C5191, in wt $\%$.

\begin{tabular}{lllll}
\hline $\mathrm{Sn}$ & $\mathrm{P}$ & $\mathrm{Pb}$ & $\mathrm{Fe}$ & $\mathrm{Zn}$ \\
\hline 5.87 & 0.22 & 0.004 & 0.001 & 0.004 \\
\hline
\end{tabular}

Total 12 specimens measuring $2 \mathrm{~mm}$ (length) $\times 1 \mathrm{~mm}$ (width) $\times 0.07 \mathrm{~mm}$ (thickness) were cut by wirecut (Electric Discharge Machine) EDM from as-received materials. Next, the specimens were divided into three groups averagely, and were subjected to various heat treatments to obtain different grain sizes. For different scale factors (greater than, less than and equal to 1), the materials were annealed in Ar protection condition with the same temperature but different holding times before furnace cooling. The grain size was measured independent of twin grains according to the standard of ASTM. The anneal conditions are presented in Table 2, and the microstructures of three different grain sizes in thickness direction are shown in Fig. 1.

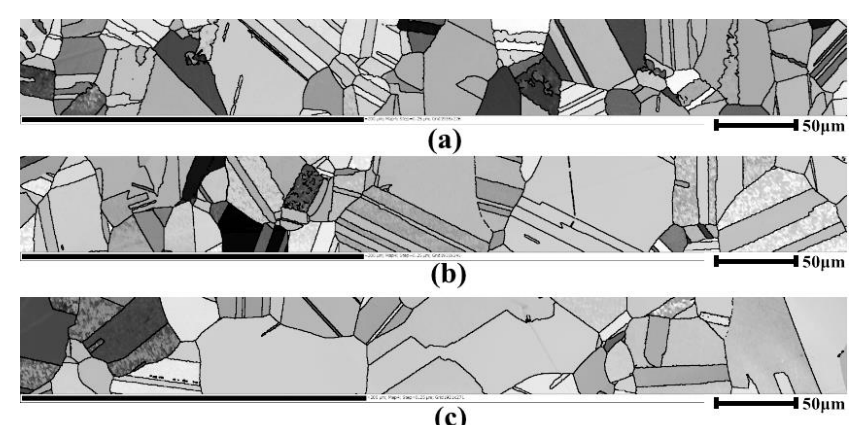

(c)

| Fig. 1. Microstructures of annealed phosphor bronze foils: (a) $T / D>1$, (b) $T / D \approx 1$ and (c) $T / D<1$. 
It can be seen that the grain size increases with holding time under the same annealing temperature. After annealing, one sample from each group was chosen for straight samples EBSD data acquisition, and the other nine specimens were conducted micro V-bending experiments and then scanned for EBSD mapping-of bended specimens.

Table 2 Heat treatment and average grain size.

\begin{tabular}{llll}
\hline Temperature $\left({ }^{\circ} \mathrm{C}\right)$ & 550 & 550 & 550 \\
\hline Time $(\mathrm{h})$ & 4 & 6 & 8 \\
Thickness, $T(\mu \mathrm{m})$ & 70 & 70 & 70 \\
Average grain size, $D(\mu \mathrm{m})$ & 57.1 & 65.7 & 103.4 \\
$T / D$ & 1.23 & 1.07 & 0.68 \\
\hline
\end{tabular}

\subsection{Micro V-bending experiment}

To investigate the relationship between $T / D$ ratios and springback phenomenon, micro V-bending was conducted on the desk-top servo press machine DT-3AW (as shown in Fig. 2) with the annealed specimens. This equipment has position accuracy of $\pm 2 \mu \mathrm{m}$ and self-designed bending models were employed. The machine can provide $30 \mathrm{KN}$ maximum force and $\pm 0.002 \mathrm{~mm}$ guidepost position accuracy. In addition, micro V-bending tooling set (punch and female die) was high-precisely manufactured from D2 tool steel with good dimensional stability $( \pm 2 \mu \mathrm{m})$ to conquer the difficulty of positioning the bending set. 


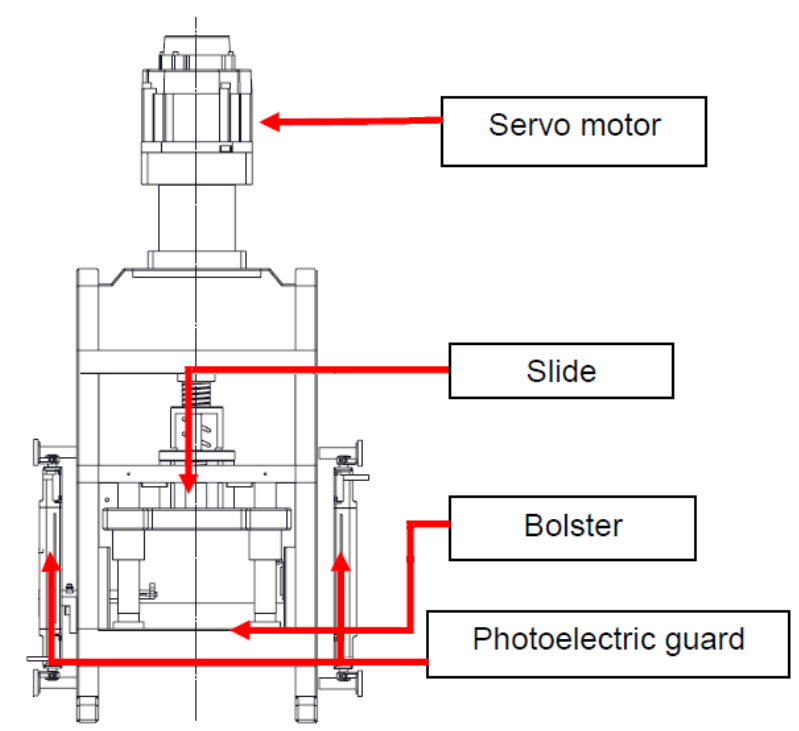

Fig. 2. Schematic of desk-top servo press machine DT-3AW.

The delicate punch and die were manufactured with 90 degree convex-concavely, and these two elements were separately installed into the upper and lower mould. The micro punch was fabricated with high dimensional accuracy of $\pm 1 \mu \mathrm{m}$ by micro-grinding, and the other pertinent geometric parameters are: die gap $=1.0 \mathrm{~mm}$, die depth $=0.5 \mathrm{~mm}$, punch corner radius $=0.01 \mathrm{~mm}$, punch stroke $=0.43 \mathrm{~mm}$. Before conducting the experiment, the surfaces between the punch and die were well lubricated by machine oil. The micro V-bending test was performed at room temperature and annealed specimens were placed in the middle of die and bended with a punch speed of $0.1 \mathrm{~mm} / \mathrm{s}$. Fig. 3 illustrates the micro V-bending process from loading to bending, and then unloading. Tight shots of these three processes were taken and key components: punch, specimen and V-die are enlarged in ellipses.

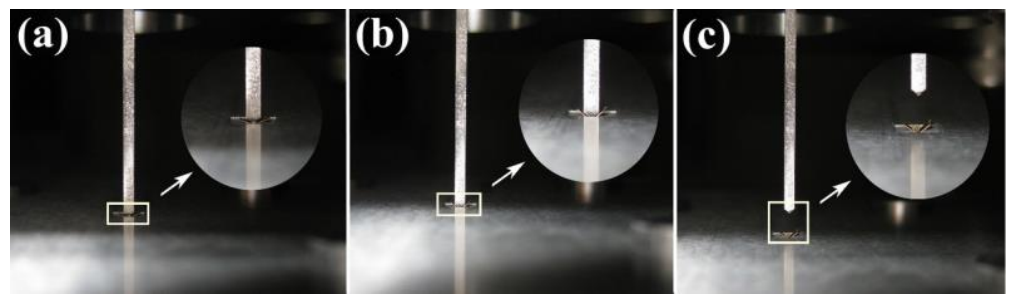

Fig. 3. Micro V-bending process: (a) loading, (b) bending, and (c) unloading. 


\subsection{EBSD observation}

After micro V-bending test, the cross section of the-rolling direction (RD) - normal direction (ND) sections for straight and bended specimens with three different $T / D$ values were polished mechanically. Due to the small geometry and the softness of specimens, an ion beam milling system (Leica EM RES102) was adopted-used to finalise polishing, qualifying the surface of specimens for EBSD test. EBSD mapping was carried out on a JEOL-JSM7001F field emission gun (FEG) scanning electron microscope (SEM), fitted with a Nordly-II (S) camera at $15 \mathrm{kV}, \sim 5 \mathrm{nA}$ and $10 \mathrm{~mm}$ working distance. A step size of $0.25 \mu \mathrm{m}$ was maintained constant for all the maps. In all maps, a minimum of 3 pixel was used to identify grain structures and misorientations $(\theta)$ less than $2^{\circ}$ were disregarded. The EBSD post-processing was carried out via HKL Channel-5.

\section{Results and discussion}

The micro V-bending results are displayed in Fig. 4 where Fig. 4(a) shows three groups nine bended specimens after unloading and springback. These specimens were then measured under microscope VHX-1000 KEYENCE (Fig. 4(b)), and each specimen was measured three times. The springback angles were obtained by deducting the bending angle 90 degree from the observed angles.

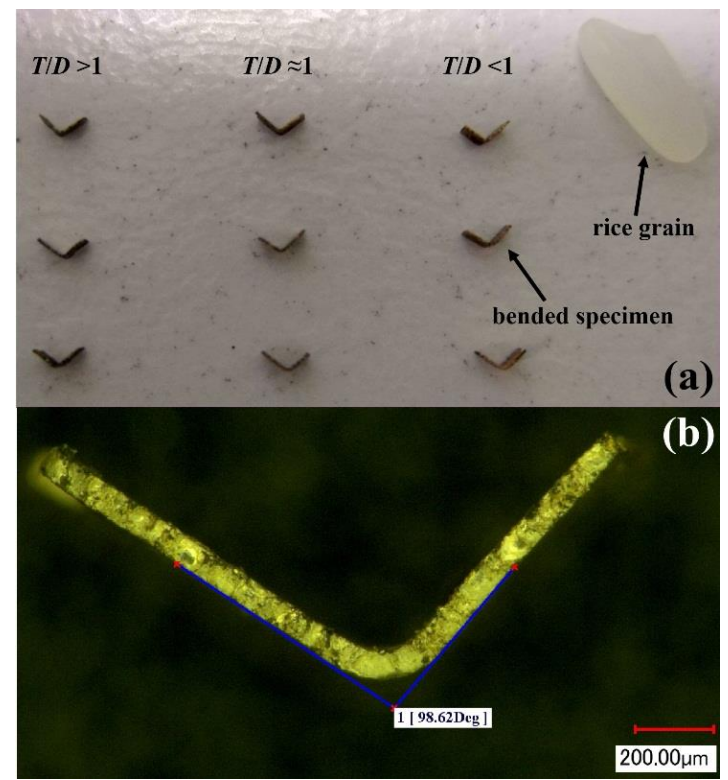


Fig. 4. Photo of (a) bended specimens and (b) a measured specimen under VHX-1000 KEYENCE.

It is interesting to notice that the lowest springback angles were obtained when $T / D \approx 1$ from Fig. 5 , as other two ratios' materials had comparatively large springback angles.

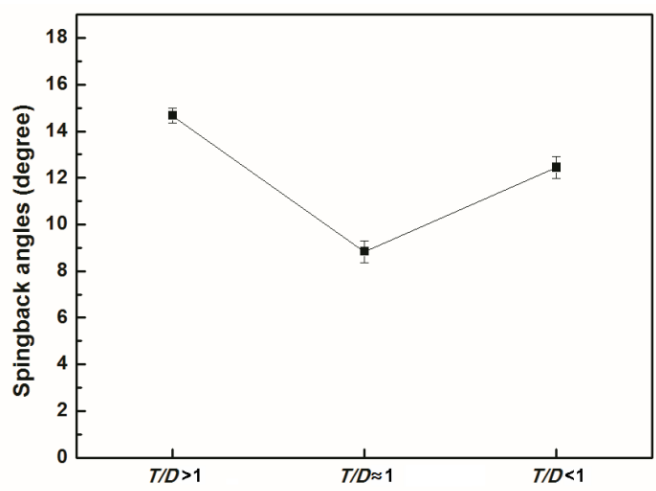

Fig. 5. Springback angles for each $T / D$ ratio

It can assure that the grain size effect has a great impact on springback results since other parameters in micro V-bending are the same. It is well--established that the material's deformation can be divided into elastic deformation and plastic deformation, and springback normally occurs when the material tries to return its original shape after being deformed. This means the degree that the material can recover to its previous geometric profile heavily depends on the ratio of elastic deformation to the whole deformation.

With the same deformation amount in micro V-bending for the three different ratios' materials, the springback angles after unloading are different, which shows that the elastic deformation during bending must notbe differentthe same. It is the least amount of elastic deformation that results in the least springback angle, and here this paper focuses on how the difference of grain size in three ratios' materials influences springback in terms of energy.

Fig. 6 shows that as the material is bent, the inner region of the material is compressed while the outer region is stretched. Generally, this will result in that the grain boundaries' density is greater on the 
inside of the material than that on the outside, and the compressive forces are less than the tensile ones on the outside layer, causing the material to try to return to its flat position.

(a)

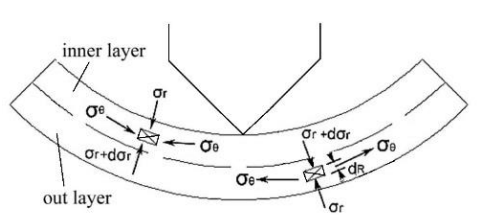

(b)

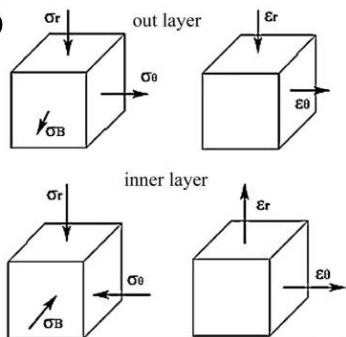

Fig. 6. Schematic of (a) the stress state, and (b) the stress and strain state of infinitesimal element during bending.

Here there are two issues need to be clarified. One is due to the different stress-strain conditions, grain reorientation in the inside layer during bending will be different with that en-in the outer surface, which will increase the asymmetry of tension and compression. This will have a direct impact on springback since different grain orientations are equipped with different Young's moduli, and the latter is decisive to springback results. The other is the interfacial energy will be different for three ratios' materials, especially when grain size has a volumetric change because ofdue to recrystallisation and twinning.

When $T / D \approx 1$, the specimen has the least springback value, which means the system has the lowest energy comparing to the other two materials. This can reasonably conclude that the $T / D \approx 1$ material has the most chemical bonds, and it also indicates that the connection among molecules in the system is the strongest. Therefore, the material is the hardest one to recovery after unloading.

After micro V-bending, it is found that the final relative frequencies of coincident site lattice (CSL) boundaries $\Sigma 3$ in all three materials are nearly the same. Fig. 7(a) shows that when the specimens are straight, the quantity of $\Sigma 3$ is related to the number of twinning grains in the materials. During the period of recovery, a large number of stacking faults were formed, leading to the nucleation of 
twinning. With the increase of annealing time, the high angle grain boundaries (HAGBs)' migration leads to the recrystallisation grain and twining growth [22]. This causes the difference of grain boundaries and twin boundaries, and it can be concluded that the $T / D>1$ material has the highest system energy since it has the most these boundaries, which means-infers thisis system is the most unstable one comparing to the other two. However, after micro V-bending, the values of twinning boundaries for each ratio's material do not show obvious difference. Although the materials are different in terms of internal grain volume, when they experienced the same degree of deformation, they ended up with the same twinning boundary features as shown in Fig. 7(b). As above mentioned, the bending process contains compression and stretching, and this severe inhomogeneous deformation can contribute to the minimisation of $\Sigma 3$. To $T / D \approx 1$ and $T / D<1$ materials, it can be seen that their boundaries' relative frequencies remain stable after bending and springback, , and $\underline{\text { Iit }}$ also found that the final relative frequencies of $\Sigma 3$ and $\Sigma 9$ are almost the same, which indicates that no matter the grain size, the relative frequencies of twin boundaries can be regarded as a system energy indicator since the system has a tendency to achieve the lowest energy state.
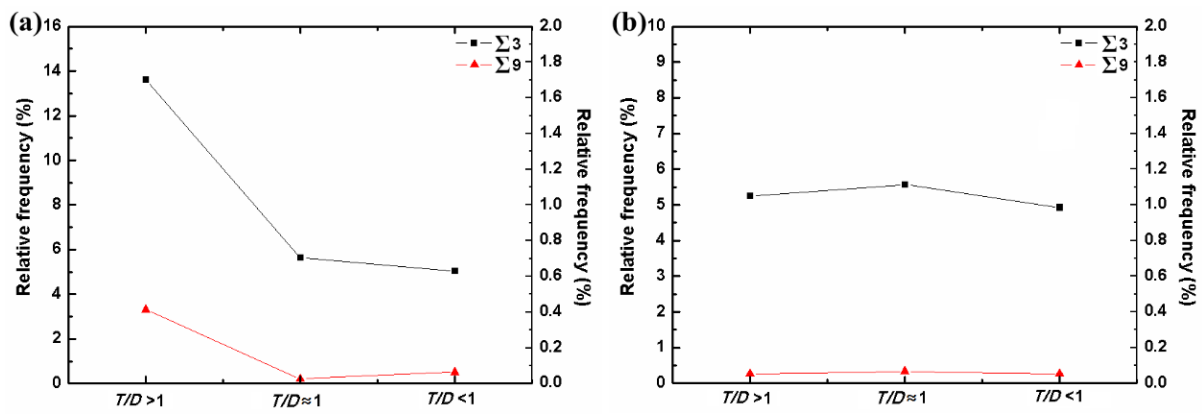

Fig. 7. (a) The frequencies of $\Sigma 3$ and $\Sigma 9$ twinning boundaries before bending, and (b) the frequencies of $\Sigma 3$ and $\Sigma 9$ twinning boundaries after bending.

With regard te The surface energy ${ }_{2}$, whichit is generated because some of the intermolecular bonds are not satisfied at the free surface _[23], plays a significant role in influencing springback. Since. This means-the loss of the number of atoms in contact and the incomplete bonding will cause surface Comment [ZJ1]: It does not make sense? energy increasing, this increment will make materials require more deformation to return to their lowest energy states.- It is well--known that the surface energy is correlated with grain orientation. 
Wulff construction in Fig. 8 shows that for f.c.c materials $\{111\}$ crystallographic planes have the lowest and $\{100\}$ have the second lowest surface energy, while $\{110\}$ planes have the highest surface energy. Grain surfaces with $\{110\}$ planes in the bended specimens are also highlighted with white solid line in ND direction IPF mapping as shown in Fig. 9, indicating that the $T / D \approx 1$ material has the least high energy surfaces during grain reorientation, which demonstrates that the $T / D \approx 1$ material has the lowest surface energy. This feature could explain why the least springback was obtained when the ratio $T / D$ was approximately equal to 1 .

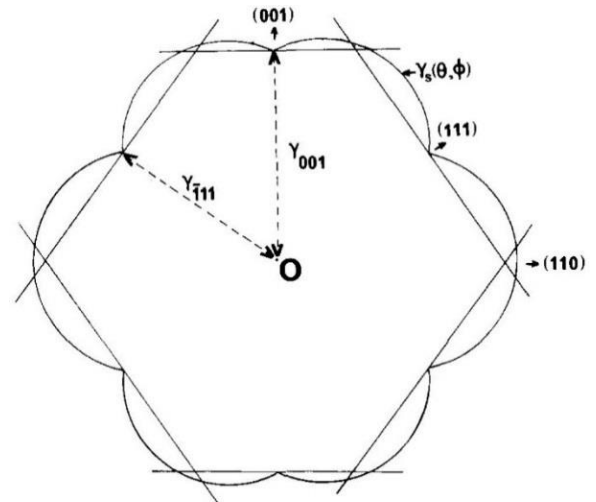

Fig. 8. A two-dimensional Wulff construction for f.c.c material on a (110) plane [24].
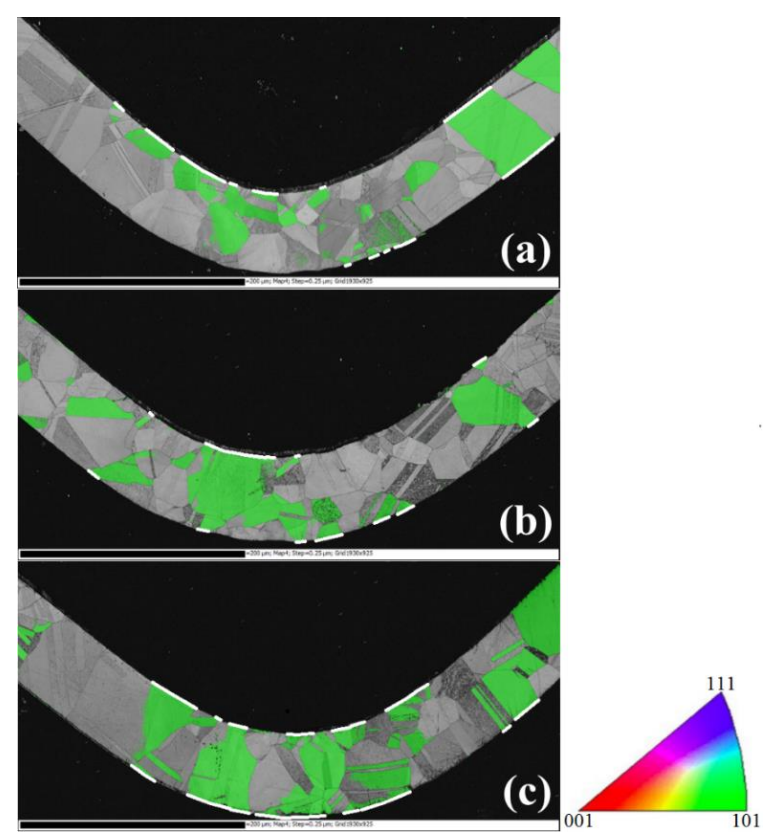

Fig. 9. Surfaces on $\{110\}$ grains in bended specimens: (a) $T / D>1$, (b) $T / D \approx 1$, and (c) $T / D<1$. 


\section{Conclusions}

In this paper, the influence of the ratio of thickness to average grain size on springback and system energy in phosphor bronze foil (f.c.c. material) was investigated by micro V-bending test and EBSD. The ratios were designed to be: $T / D>1$ (1.23), $T / D \approx 1$ (1.07) and $T / D<1(0.68)$. The following conclusions are obtained:

1. Comparing to the $T / D \approx 1$ and $T / D<1$ materials, the $T / D>1$ material has the highest system energy due to the most grain boundaries and twin boundaries.

2. Despite the difference of twin boundaries $\Sigma 3$ relative frequencies before micro V-bending, the final twin boundary features are almost the same after bending. This shows that the relative frequency of $\Sigma 3$ can be regarded as an indicator for the system energy.

3. The $T / D \approx 1$ material has the least springback angle. Because the least $\{110\}$ planes were obtained during grain reorientation, this enables the $T / D \approx 1$ material has the lowest surface energy, which could contribute to the least springback.

\section{Acknowledgements}

The authors would like to thank the Australia Research Council (ARC) for its financial support. We also acknowledge Dr. Mitchell Nancarrow from UOW Electron Microscope Centre (EMC) for his technical assistance.

\section{References}

1. F. Vollertsen, Categories of size effects. Production Engineering, 2008. 2(4): p. 377-383.

2. M. Geiger, M. Kleiner, R. Eckstein, N. Tiesler, and U. Engel, Microforming. CIRP AnnalsManufacturing Technology, 2001. 50(2): p. 445-462.

3. U. Engel and R. Eckstein, Microforming-from basic research to its realization. Journal of Materials Processing Technology, 2002. 125: p. 35-44.

4. F. Vollertsen, H.S. Niehoff, and Z. Hu, State of the art in micro forming. International Journal of Machine Tools and Manufacture, 2006. 46(11): p. 1172-1179. 
5. M. Fu and W. Chan, A review on the state-of-the-art microforming technologies. The International Journal of Advanced Manufacturing Technology, 2013. 67(9-12): p. 2411-2437.

6. A. Karafillis and M. Boyce, Tooling design in sheet metal forming using springback calculations. International Journal of Mechanical Sciences, 1992. 34(2): p. 113-131.

7. A.P. Karafillis and M.C. Boyce, Tooling and binder design for sheet metal forming processes compensating springback error. International Journal of Machine Tools and Manufacture, 1996. 36(4): p. 503-526.

8. K. Li, W. Carden, and R. Wagoner, Simulation of springback. International Journal of Mechanical Sciences, 2002. 44(1): p. 103-122.

9. W. Carden, L. Geng, D. Matlock, and R. Wagoner, Measurement of springback. International Journal of Mechanical Sciences, 2002. 44(1): p. 79-101.

10. R. Cleveland and A. Ghosh, Inelastic effects on springback in metals. International journal of plasticity, 2002. 18(5): p. 769-785.

11. J.-T. Gau, C. Principe, and M. Yu, Springback behavior of brass in micro sheet forming. Journal of Materials Processing Technology, 2007. 191(1): p. 7-10.

12. J. Liu, M. Fu, J. Lu, and W. Chan, Influence of size effect on the springback of sheet metal foils in micro-bending. Computational Materials Science, 2011. 50(9): p. 2604-2614.

13. Z. Fang, Z. Jiang, D. Wei, and X. Liu, Study on springback in micro V-bending with consideration of grain heterogeneity. The International Journal of Advanced Manufacturing Technology, 2014. 78(5-8): p. 1075-1085.

14. S. Gupta, A. Ma, and A. Hartmaier, Investigating the influence of crystal orientation on bending size effect of single crystal beams. Computational Materials Science, 2015. 101: p. 201-210.

15. C.-P. Jiang and C.-C. Chen, Grain size effect on the springback behavior of the microtube in the press bending process. Materials and Manufacturing Processes, 2012. 27(5): p. 512-518.

16. C.-C. Chen and C.-P. Jiang, Grain size effect in the micro-V-bending process of thin metal sheets. Materials and Manufacturing Processes, 2011. 26(1): p. 78-83.

17. J. Wang, M. Fu, and J. Ran, Analysis of the Size Effect on Springback Behavior in Micro Scaled U - Bending Process of Sheet Metals. Advanced Engineering Materials, 2014. 16(4): p. 421-432.

18. A. Diehl, U. Engel, and M. Geiger, Mechanical properties and bending behaviour of metal foils. Proceedings of the Institution of Mechanical Engineers, Part B: Journal of Engineering Manufacture, 2008. 222(1): p. 83-91.

19. L. Wang, G. Huang, T. Han, E. Mostaed, F. Pan, and M. Vedani, Effect of twinning and detwinning on the spring-back and shift of neutral layer in AZ31 magnesium alloy sheets during V-bend. Materials \& Design, 2015. 68: p. 80-87.

20. L. Wang, G. Huang, F. Pan, and M. Vedani, Effect of strain rate on the shift of neutral layer in AZ31B alloys during V-bending at warm conditions. Materials Letters, 2015. 143: p. 44-47.

21. Z. Ma, G. Tong, F. Chen, Q. Wang, and S. Wang, Grain size effect on springback behavior in bending of Ti-2.5 Al-1.5 Mn foils. Journal of Materials Processing Technology, 2015. 224: p. 11-17.

22. C.V. Kopezky, V.Y. Novikov, L. Fionova, and N. Bolshakova, Investigation of annealing twins in fcc metals. Acta Metallurgica, 1985. 33(5): p. 873-879.

23. R.J. Stokes and D.F. Evans, Fundamentals of interfacial engineering. 1997: John Wiley \& Sons.

24. L. Marks, Modified Wulff constructions for twinned particles. Journal of Crystal Growth, 1983. 61(3): p. 556-566. 